\title{
Comparison of physical activity as an obesity-related behavior between immigrants and native-born US adults
}

\author{
Joyce T. Alese ${ }^{1} \&$ Olatunji B. Alese (iD) ${ }^{2 凶}$
}

\begin{abstract}
Non-communicable diseases and chronic conditions such as obesity constitute significant public health issues in the United States (US) and globally. A major proximal determinant of obesity is physical activity, and related behavior. Limited data however exists comparing physical activity levels of US immigrants with those of native-born adults. This study aimed to compare US immigrants and native-born adults regarding associations of physical activity behavior and obesity. We analyzed data from the Health Information National Trends Survey. Outcomes of interest were various indicators of physical activity. Bivariate analyses and multivariate logistic regression models were utilized in describing demographics, weight distribution, and associations between variables of interest. A total of 3,185 individuals participated in the survey. Male to female ratio was 1.6 and $17 \%$ of the participants were immigrants. The mean age was 51 years $(S D \pm 15)$ for immigrants and 55 years (SD \pm 16 ) for native-born respondents. Among immigrants, the racial distribution was 55.3\% Hispanic, $18.9 \%$ Asian, $14.7 \%$ White, $9.9 \%$ Black, and 1.3\% other races. Immigrants were less likely than non-immigrants to spend $6 \mathrm{~h}$ or more a day on sedentary leisure activities (adjusted $\mathrm{OR}=0.64 ; 95 \% \mathrm{Cl}$ : 0.42-0.97; $p=0.0350$ ). Also, immigrants were more likely than non-immigrants to engage in physical activity of at least moderate intensity, at least once a week (adjusted $\mathrm{OR}=1.48 ; 95 \% \mathrm{Cl}$ : 1.07-2.05; $p=0.0192$ ). Compared to native-born adults, US immigrants appear to have healthier lifestyles regarding physical activity behavior. Strategies to sustain such tendencies among immigrants will promote health and reduce overall risks of obesity and other chronic diseases in the US. Researchers, practitioners and policy makers should develop targeted strategies and focus attention on keeping immigrants in the loop of positive health behavior, while encouraging US adults to engage in more physical activity. Further studies are needed to determine the effects of various socio-economic, demographic and cultural factors that impact proximal determinants of obesity.
\end{abstract}

\footnotetext{
${ }^{1}$ Georgia State University, Atlanta, USA. ${ }^{2}$ Winship Cancer Institute of Emory University, Atlanta, USA. ${ }^{凶}$ email: oalese@emory.edu
} 


\section{Introduction}

besity is associated with significant morbidity and mortality, resulting in enormous economic costs. In 2012, an estimated $\$ 190.2$ billion (21\% of annual US medical spending) was projected for obesity-related illnesses in the US (Cawley and Meyerhoefer, 2012). Cardiovascular disease, hyperlipidemias, type 2 diabetes mellitus, sleep disorders, and depression are more common among patients with obesity, compared to the general population (Khaodhiar et al., 1999, Wadden et al., 1996). Numerous studies have explored factors related to the etiology of obesity. These factors have been broadly categorized into genetic, environmental and behavioral (Weinsier et al., 1998). Behavioral factors are lifestyle choices that either promote or prevent obesity and constitute part of the multifaceted proximal determinants of obesity. Balanced caloric intake and regular physical activity are among the well-recognized lifestyle choices that prevent overweight and obesity (American Heart Association Nutrition et al., 2006).

Moreover, immigration to the US has been on a steady increase until recently. The population of immigrants in the US increased from 9.6 million in 1970 to 31.1 million in 2000 (Grieco et al., 2010) and immigrants currently represent a substantial population group in the US (Cadena, 2013). Research shows that in spite of lower income and educational attainment, adult US immigrants have lower risks of obesity compared with their nativeborn counterparts; especially in the early years of immigration (Wen et al., 2013, Akresh, 2008). However, there is a paucity of data in the literature exploring differences that may exist between US immigrants and native-born adults regarding obesity-related behavior. Specifically, data comparing immigrants and nonimmigrants as regards proximal determinants of obesity is very limited. A prior study, evaluating diet and exercise counseling, found that immigrants were less likely than native-born adults to discuss their dietary (18\% vs. $24 \%)$ and physical activity (19\% vs. $23 \%$ ) routines and concerns with health care providers (Goel et al., 2004). The study emphasized the importance of early intervention with diet and physical activity in preventing weight gain, obesity, and related chronic illnesses among immigrant subgroups.

Compared to native-born US adults, US immigrants have been shown to have lower obesity risks, especially in the first few years following immigration. Antecol et al. found that at entry into the US, female and male immigrants had obesity rates roughly two and five percentage points lower than native-born women and men respectively (Antecol and Bedard, 2006). This observed lower risk of obesity cuts across various immigrant subgroups, including Latinos (Akresh, 2008), Asians (Ng et al., 2009), and persons of African descent (Bennett et al., 2007). Furthermore, the observed lower risk of obesity among immigrants holds true in spite of lower income and educational attainment (Wen et al., 2013; Akresh, 2008). The latter finding is somewhat at variance with the established direct correlation between lower socioeconomic/educational indices and the prevalence of obesity in native-born US residents. Explanations proffered in literature for this "immigrant paradox" include a 'healthy immigrant' effect (HIE), the protective influence of strong social networks and family ties, and even a reporting bias (Cespedes et al., 2013). The observed lower risk of obesity among US immigrants is all the more interesting in the light of increasing rates of obesity in countries like Mexico that account for a high proportion of immigrants to the US (Ogden et al., 2012).

However, morbidity and mortality risks from various diseases and conditions eventually change for immigrants as their length of residence in the US increases (Singh and Miller, 2004), and obesity is no exception. The risk of obesity among immigrants is known to increase as the length of stay increases. In their study,
Antecol et al. further reported that female and male immigrants gain enough weight to develop obesity rates comparable with that of native-born Americans, within 10 and 15 years of arrival respectively (Antecol and Bedard, 2006). Moreover, similar to the observed lower risk of obesity for immigrants at entry, the observed increased risk of obesity with increased length of residence also cuts across various immigrant subgroups. A study found that Latinos who had stayed in the US for 15 or more years developed about a four-fold risk of obesity compared to those with less than 5 years of stay (Kaplan et al., 2004). Another study observed that immigrant women of Puerto Rican origin who had been in the US for 10 years or more had a $40 \%$ prevalence of obesity, compared to a prevalence of $29 \%$ for those who had been in the US less than a year (Himmelgreen et al., 2004). Furthermore, in a nationally representative sample of 5230 US immigrants of various racial and ethnic sub-groups, there was a direct correlation between length of residence and risk of obesity; 15 or more years was associated with increased risk of obesity (OR 1.31; 95\% CI 1.03-1.65) (Koya and Egede, 2007).

The prevalence of obesity in the US is known to differ among groups and sub-populations (Juarez et al., 2010). Among 10,792 adults included in the 2001-2016 National Health and Nutrition Examination Survey, adult male participants domiciled in less populated metropolitan areas had a higher age-adjusted prevalence of obesity compared with those in areas with population $>1$ million (42.4\% vs. $31.8 \%$ ) (Hales et al., 2018). The study also found that observed disparity was influenced by age, socioeconomic status, educational attainment, and racial group. Hence, determination of risks specific to sub-populations as well as comparisons of obesity-related behavior among diverse groups will promote the planning of targeted interventions for health promotion and disease prevention. This study aimed to describe demographic characteristics, weight distribution, and distributions of specific obesity-related behavior (physical activity) in a nationally representative sample of U.S. adults surveyed in 2013. Secondarily, we aimed to estimate associations between nativity status (immigrant vs. native-born) and specific obesity-related behavior (physical activity) among adults in the U.S.

\section{Methods}

Materials. A nationally representative sample of individuals in the US 18 years or older were surveyed in the Health Information National Trends Survey (HINTS). Conducted by mail from September 2013 through December 2013 using a protocol similar to that utilized in previous cycles (Agaku et al., 2014), data was collected on the American public's need for, access to, and use of health-related information; as well as data on health-related behaviors, perceptions and knowledge (Nelson et al., 2004). The vast majority of the survey items in the HINTS questionnaires are derived from instruments used for evaluation of general health in existing national-level surveys. Although a lot of attention is given to cancer, other domains assessed by the survey include nutrition and dietary behavior, physical activity, food security, health status, health care, and health information seeking. This analysis of the HINTS 4 cycle 3 dataset was conducted under Georgia State University Institutional Review Board (IRB)-exempted protocols.

Measures. The written report presented gives statistics for variables of interest (demographics and proximal determinants of obesity) obtained from the dataset. The independent variable of main interest in the analyses was the nativity status of participants: immigrant versus native-born. The dependent variables evaluated for the analyses included several indicators of the usual physical activity level of participants, as well as BMI. Indicators 
selected to represent the usual physical activity levels of participants included sitting time spent on television (TV)/computer games/web surfing, participation in physical exercise of at least moderate intensity, and participation in muscle training exercise. Covariates we included were gender, age, level of education, race/ ethnicity, income ranges, disability and marital status.

Statistical analysis and procedure. We performed univariate analyses to describe the distribution of socio-demographic characteristics of survey participants by nativity status. Wald ChiSquare tests (for categorical variables), and $t$ test for differences in means (for the continuous variable 'age') were used to determine differences in distributions of demographic variables among immigrants and non-immigrants. Bivariate analyses results were utilized to describe physical activity behavior as well as BMI distribution among immigrants and non-immigrants; and $p$ values $<0.05$ were taken as statistically significant. Multivariate logistic regression models were used to obtain adjusted odds ratios (AOR) and 95\% confidence intervals (95\% CI) for associations between nativity status and indicators of usual physical activity behavior, which included average time spent on TV/ games/web surfing, participation in moderate intensity exercise and participation in strength training exercises. The variable 'Disabled' was derived from responses of participants to specific survey items that inquired about various forms of disability including blindness, deafness, difficulty with walking/dressing/ bathing/errands, as well as emotional disability. In all our multivariate models, $p$-values $<0.05$ and $95 \% \mathrm{CI}$ around AOR were used to determine statistical significance. All analyses were done using SAS 9.3 (SAS Institute, Cary, NC).

\section{Results}

Demographic characteristics. A total of 3,185 individuals participated in the HINTS 4 cycle 3 survey, but 3131 respondents were included in this analysis based on the pre-specified inclusion criteria. Sixty-one percent of included participants were female, giving an overall male to female ratio of 1.6. With a mean age of 54.68 years $(\mathrm{SD} \pm 16.5)$, the distribution of age group was $18-34$ years $(13.82 \%), 35-49$ years $(23.10 \%), 50-64$ years $(34.72 \%)$, and 65 years or older $(28.36 \%$-Table 1$)$. About $52 \%$ of participants were high school graduates or had attended some college. An estimated $52.24 \%$ of respondents were employed, $5.97 \%$ were unemployed, and $41.79 \%$ were either retired or not in the work force (disabled, homemaker or student). Majority of the respondents were Non-Hispanic Whites (58\%), followed by Hispanics (18.75\%), Blacks (15.45\%), and Asians (4.18\%), while $3.49 \%$ were of other races. Female native-born respondents constituted about half (51.5\%) of all participants in the survey.

Majority of the participants were native-born (83\%). About $60 \%$ of immigrants and $62 \%$ of native-born respondents were female. The mean age for immigrants was 51 years $(S D \pm 15)$, and that for native-born participants was 55 years $(\mathrm{SD} \pm 16)$. About $55 \%$ of immigrants were Hispanic, while most native-born respondents $(67.3 \%)$ were White. Half $(50 \%)$ of native-born respondents were married or living as married compared to $60 \%$ of immigrants.

About $39 \%$ of immigrants had college degrees or higher, compared to $37.4 \%$ of native-born participants. Roughly $21 \%$ of immigrants had less than high school education compared to $7.2 \%$ of native-born respondents. Forty-eight percent of immigrants reported owning their homes compared to $69 \%$ of nativeborn respondents. Among immigrants, $82.64 \%$ had lived in the US for more than 10 years, $10.74 \%$ had lived in the US for $6-10$ years and $6.61 \%$ had lived in the US for 5 years or less.
Weight and physical activity by nativity status. Table 2 shows BMI categories by nativity status, as well as distributions of physical activity variables by nativity status of participants. The variables presented were chosen as specific indicators of the physical activity level of participants, as previously described in our "Methods" section. Regarding BMI, 33.06\% of participants in the entire cohort $(n=3064)$ were obese and $33.78 \%$ were overweight. Most immigrants $(36.3 \%)$ were in the normal weight category while most native-born respondents (34.4\%) were in the obese category. An estimated $25.65 \%$ of immigrants were obese compared to $34.4 \%$ of native-born respondents.

Most participants in the cohort spent $<5 \mathrm{~h}$ per day (on the average) sitting to watch TV, play computer games or surf the web: $80.4 \%$ of immigrants and about $71.7 \%$ of the native-born. One percent of immigrants and $1.6 \%$ of native-born respondents spent $15 \mathrm{~h}$ or more per day on these leisure activities. About $42 \%$ of immigrants and $38.3 \%$ of native-born participants took part in physical exercise of at least moderate intensity 1-3 times per week. Meanwhile, $22.6 \%$ of immigrants and $26.3 \%$ of native-born participants did not engage in physical activity of at least moderate intensity.

Among participants who had some weekly exercise of at least moderate intensity, the commonest length of exercise time was $30-60$ min per day; $73.2 \%$ of immigrants and $76.2 \%$ of the native-born who exercised were in this category. Also, $46.36 \%$ of immigrants vs. $43.26 \%$ of native-born participants took part in muscle strength training exercises at least once a week; while $53.64 \%$ of immigrants vs. $56.74 \%$ of native-born respondents did not engage in any form of muscle training exercise.

Associations between nativity status and outcome variables of interest. Multivariate logistic regression analyses were conducted for associations between nativity status and time spent on sedentary leisure activities; nativity status and moderate intensity physical exercise; as well as nativity status and muscle strength training (Table 3). After adjusting for gender, age group, race/ethnicity, level of education, marital status and income category, immigrants were less likely than native-born respondents to spend $6 \mathrm{~h}$ or more a day sitting to watch TV, play computer games and/or surf the web (Adjusted $\mathrm{OR}=0.64 ; 95 \% \mathrm{CI}: 0.42-0.97 ; p=0.0350)$. Also, immigrants were more likely than native-born respondents to engage in physical activity of at least moderate intensity, at least once a week (Adjusted OR $=1.48 ; 95 \% \mathrm{CI}: 1.07-2.05 ; p=0.0192$ ). Additionally, although the association was not statistically significant, immigrants were more likely than native-born participants to engage in muscle strength training at least one day per week (Adjusted $\mathrm{OR}=1.28 ; 95 \%$ CI: 0.98-1.67; $p=0.0757)$.

Our multivariate analyses also revealed that participants in the $65+$ age group were more likely to spend 6 or more hours per day sitting down for leisure activities (Adjusted OR $=1.71 ; 95 \% \mathrm{CI}$ : $1.16-2.52 ; p=0.0066$ ). Black participants were also more likely to engage in sedentary leisure activities for 6 or more hours per day (Adjusted OR $=1.73$; 95\% CI: $1.28-2.35$; $p=0.0004$ ). Meanwhile, participants who earned $\$ 100,000$ or above were less likely to spend 6 or more hours on sedentary leisure activities (Adjusted $\mathrm{OR}=0.45$; 95\% CI: 0.26-0.80; $p=0.0061$ ).

Females were less likely than males to engage in physical exercise of at least moderate intensity at least once a week (Adjusted OR =0.74; 95\% CI: 0.60-0.91; $p=0.0039$ ). Compared to participants with less than high school education, participants with high school diploma and those who had some college education (Adjusted OR $=1.45 ; 95 \% \mathrm{CI}: 1.02-2.05 ; p=0.0375$ ), 
Table 1 Demographic characteristics of the HINTS survey participants.

\begin{tabular}{|c|c|c|c|c|}
\hline Mean (Min-Max) & $55.39(18-105)$ & $51.25(18-92)$ & 3082 & \\
\hline $18-34$ & $348(13.62)$ & $78(14.91)$ & $426(13.82)$ & \multirow[t]{4}{*}{$<0.0001$} \\
\hline $35-49$ & $533(20.86)$ & $177(33.84)$ & $710(23.10)$ & \\
\hline $50-64$ & $907(35.50)$ & $161(30.78)$ & $1068(34.72)$ & \\
\hline 65 or more & $767(30.02)$ & $107(20.46)$ & $874(28.36)$ & \\
\hline \multicolumn{5}{|l|}{ Gender } \\
\hline Male & $969(37.97)$ & $214(40.92)$ & $1183(38.6)$ & \multirow[t]{2}{*}{0.21} \\
\hline Female & $1583(62.03)$ & $309(59.08)$ & $1892(61.4)$ & \\
\hline \multicolumn{5}{|l|}{ Race/ethnicity } \\
\hline Non-Hispanic White & $1513(67.30)$ & $70(14.71)$ & $1583(58.13$ & \multirow[t]{4}{*}{$<0.0001$} \\
\hline African American & $374(16.64)$ & $47(9.87)$ & $421(15.45)$ & \\
\hline Hispanic & $248(11.03)$ & $263(55.25)$ & $511(18.75)$ & \\
\hline Asian & $24(1.07)$ & $90(18.91)$ & $114(4.18)$ & \\
\hline More than 10 years & $\mathrm{n} / \mathrm{a}$ & $400(75.04)$ & $\mathrm{n} / \mathrm{a}$ & \multirow{2}{*}{0.23} \\
\hline Unknown & $\mathrm{n} / \mathrm{a}$ & $49(8.65)$ & $\mathrm{n} / \mathrm{a}$ & \\
\hline \multicolumn{5}{|l|}{ Level of education } \\
\hline Less than high school & $187(7.28)$ & $110(20.91)$ & $297(9.59)$ & \multirow[t]{3}{*}{$<0.0001$} \\
\hline High school graduate or some college & $1419(55.28)$ & $211(40.11)$ & $1630(52.71)$ & \\
\hline College graduate or higher & $961(37.44)$ & $205(38.97)$ & $1166(37.69)$ & \\
\hline \multicolumn{5}{|l|}{ Marital status } \\
\hline Married or living as married & $1280(50.02)$ & $313(59.85)$ & $1593(51.69)$ & \multirow[t]{2}{*}{$<0.0001$} \\
\hline Not married and not living as married & $1279(49.98)$ & $210(40.15)$ & $1489(48.31)$ & \\
\hline \multicolumn{5}{|l|}{ Occupation status } \\
\hline Employed & $1299(51.69)$ & $282(54.86)$ & $1581(52.24)$ & \multirow[t]{3}{*}{$<0.0001$} \\
\hline Unemployed & $124(4.93)$ & $57(11.09)$ & $181(5.97)$ & \\
\hline Retired & $710(28.25)$ & $92(17.90)$ & $802(26.45)$ & \\
\hline Does not own home & $767(30.85)$ & $264(51.76)$ & $1031(34.44)$ & $<0.0001$ \\
\hline $\begin{array}{l}\text { aMissing values were excluded from all analyses. } \\
\text { bWald Chi-Square tests (categorical variables) and } t \\
\text { cContinuous variable; Min-max = minimum age to } \\
\text { dRace category 'others' includes American Indian, A } \\
\text { eOccupation status 'others' includes homemaker, stu }\end{array}$ & $\begin{array}{l}\text { inuous variable) for differences in } \\
\text { age. } \\
\text { e, Pacific Islander and others. } \\
\text { oled and others. }\end{array}$ & of selected demographic $v$ & nativity status. & \\
\hline
\end{tabular}

as well as those with at least a college degree (Adjusted $\mathrm{OR}=2.23$; 95\% CI: $1.51-3.29 ; p<0.0001$ ) were more likely to engage in some moderate intensity exercise at least weekly. Participants in the $65+$ age group were less likely to engage in moderate intensity exercise weekly (Adjusted $\mathrm{OR}=0.37 ; 95 \% \mathrm{CI}: 0.26-0.52 ; p<0.0001$ ). Blacks were also less likely to engage in moderate intensity exercise every week (Adjusted $\mathrm{OR}=0.67 ; 95 \% \mathrm{CI}$ : 0.51-0.88; $p=0.0038)$.

Participants who earned $\$ 100,000$ or above were more likely to engage in muscle training exercises at least weekly (Adjusted $\mathrm{OR}=1.25$; 95\% CI: $0.89-1.77 ; p=0.0061$ ). Females were less likely than males to engage in muscle strength training at least once a week (Adjusted OR $=0.75 ; 95 \% \mathrm{CI}: 0.63-0.89 ; p=0.0009$ ), and participants in the $65+$ age group were less likely to engage in weekly muscle training exercises (Adjusted OR $=0.52 ; 95 \%$ CI: 0.40-0.69; $p$ $<0.0001$ ). Overall, level of education was directly and significantly correlated with participation in moderate intensity exercise but not with muscle strength training.
After including and controlling for disability in our additional models, immigrants were still more likely than native born respondents to engage in physical activity of at least moderate intensity, at least once a week (Adjusted $\mathrm{OR}=1.46 ; 95 \% \mathrm{CI}$ : $1.05-2.02 ; p=0.0242)$. Furthermore, after controlling for disability in our models, immigrants were still more likely than native-born participants to engage in muscle strength training at least one day per week but the association was not statistically significant (Adjusted OR $=1.266$; 95\% CI: 0.97-1.66; $p=0.0867$ ).

\section{Discussion}

It is known that immigrants currently make up about one-sixth of the US population and this was reflected in the composition of participants in the HINTS 4 Cycle 3 survey which included roughly $17 \%$ immigrants. The results of our analysis showed that most US immigrants are Hispanic, corroborating previous reports that Mexicans make up the largest population of immigrants to 
Table 2 Distribution of BMI and indicators of physical activity level by nativity status.

\begin{tabular}{|c|c|c|c|c|}
\hline Selected variables & Immigrant (17\%) $n=533$ & Native-born $(83 \%) n=2598$ & Total $^{\mathbf{a}} n=3131$ & $p$-value ${ }^{b}$ \\
\hline BMI categories & & & & $<0.0001$ \\
\hline Underweight $(<18.5)$ & $16(3.21)$ & $36(1.43)$ & 52 & \\
\hline Normal weight (18.5-24.9) & $181(36.27)$ & $773(30.63)$ & 954 & \\
\hline Obese $(\geq 30)$ & $128(25.65)$ & $869(34.43)$ & 997 & \\
\hline \multicolumn{5}{|c|}{ Average daily hours spent sitting (TV/movies/web/computer games)c } \\
\hline None & $18(3.67)$ & $43(1.73)$ & 61 & $<0.0001$ \\
\hline 15 or more hours per day & $5(1.02)$ & $41(1.65)$ & 46 & \\
\hline \multicolumn{5}{|c|}{ Physical activity of moderate intensity per weekc } \\
\hline None & $118(22.61)$ & $673(26.28)$ & 791 & 0.1768 \\
\hline $1-3$ times per week & $217(41.57)$ & $982(38.34)$ & 1199 & \\
\hline 4 or more times per week & $187(35.82)$ & $906(35.38)$ & 1093 & \\
\hline \multicolumn{5}{|c|}{ Length of exercise per day of exercise ${ }^{d}$} \\
\hline
\end{tabular}

Table 3 Associations between nativity status and physical activity level among participants.

\section{Participant characteristics \\ TV/games/web $\geq 6$ h per day ${ }^{a}$}

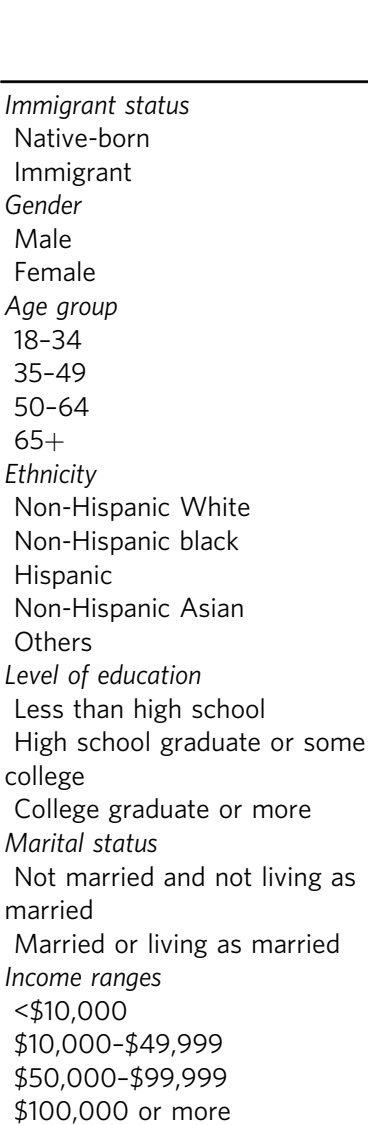
$\operatorname{AOR}^{b}(95 \% \mathrm{Cl})$

Ref

Ref

$0.92(0.72-1.17) \quad 0.4982$

Ref

$\begin{array}{cc}0.969(0.64-1.47) & 0.8813 \\ 1.44(0.995-2.098) & 0.0535\end{array}$

$1.71(1.16-2.52) \quad 0.0066$

$$
\text { Ref }
$$

$1.73(1.28-2.35)$

$0.84(0.57-1.24)$

$1.45(0.72-2.93)$

$2.05(1.21-3.46)$

0.0004

0.3897

0.2973

0.0075

Ref

$0.89(0.59-1.33)$

0.5568

$0.48(0.30-0.77)$

0.0022

Ref

$0.84(0.66-1.08)$

0.1830

Ref

$1.03(0.70-1.52)$

$0.66(0.42-1.04)$

$0.45(0.26-0.80)$

0.0733

0.0061
$0.64(0.42-0.97)$
Moderate intensity exercise (at least one day per week) ${ }^{a}$

AOR $^{b}(95 \% \mathrm{Cl}) \quad p$-value

Ref

1.48 (1.07-2.05)

Ref

$0.74(0.60-0.91) \quad 0.0039$

Ref

$0.54(0.38-0.77)$

$0.58(0.42-0.82)$

$0.37(0.26-0.52)$

0.0006

0.0016

$<0.0001$

Ref

$0.67(0.51-0.88) \quad 0.0038$

$0.77(0.57-1.04) \quad 0.0911$

$0.64(0.37-1.11) \quad 0.1120$

$0.87(0.52-1.45) \quad 0.5892$

Ref

$1.45(1.02-2.05) \quad 0.0375$

$2.23(1.51-3.29) \quad<0.0001$

Ref

$1.00(0.81-1.24)$

0.9969

$0.71(0.59-0.85)$

0.0002

Ref

$\begin{array}{cccc}0.79(0.56-1.12) & 0.1876 & 0.97(0.71-1.32) & 0.8412 \\ 1.01(0.68-1.50) & 0.9625 & 1.72(1.17-2.53) & 0.1979 \\ 1.23(0.78-1.96) & 0.3719 & 1.25(0.89-1.77) & 0.0061\end{array}$

Muscle strength training (at least one day per week) ${ }^{a}$

$\mathrm{AOR}^{\mathrm{b}}(95 \% \mathrm{Cl}) \quad p$-value

Ref

$1.28(0.98-1.67) \quad 0.0757$

Ref

$0.75(0.63-0.89) \quad 0.0009$

Ref

$0.85(0.65-1.11) \quad 0.2348$

$0.67(0.52-0.86) \quad 0.0016$

$0.52(0.40-0.69)<0.0001$

Ref

$1.09(0.85-1.40) \quad 0.4813$

$0.97(0.76-1.28) \quad 0.9155$

$0.75(0.47-1.19) \quad 0.2247$

$1.48(0.95-2.29) \quad 0.0817$

$0.96(0.68-1.34) \quad 0.7951$

$1.21(0.84-1.74) \quad 0.3004$

$1.25(0.89-1.77)$

0.1979

andicator of physical activity behavior selected as an outcome variable; AOR adjusted odds ratio.

bAdjusted for gender, age group, race/ethnicity, level of education, marital status and income ranges; $95 \% \mathrm{Cl}=95$ percent confidence interval; Ref $=$ Reference category; Missing values were excluded from all analyses. 
the US (Camarota, 2012). The analysis also showed that compared to native-born respondents, a greater proportion of immigrants had college degrees or higher level of education. Historically, compared to native-born residents, US immigrants have been known to enjoy a benefit regarding having at least a college level of education (Connor and Ruiz, 2019; Jacobs, 2019).

The prevalence of obesity has more than doubled over the last three decades in most regions of the world (Chooi et al., 2019). While the rise is leveling off in most western economies, changes in demographic, social and economic indices contribute to the disturbing pattern in most developing countries. The morbidity and mortality from associated conditions such as diabetes mellitus for example, is projected to place significant financial burden on emerging economies at a time when they could least cope (Prentice, 2006). Some of the current efforts at combating this scourge include electronic and mobile health interventions to promote physical activity, with encouraging results (Muller et al., 2016). Understandably, the cost implications of such and other interventions (e.g. regular health screenings) have to be adequately designed with regards to the healthcare expenditures of national health systems (Vuong, 2018).

The alarming trends of obesity in the US was also apparent in our results. An estimated $34.4 \%$ of native-born participants were obese, reflecting the current reported obesity prevalence rate of 34.9\% (Ogden et al., 2014). Although lower than the proportion among native born adults, a $25 \%$ proportion of obese participants among immigrants is still a cause for concern. Observed indicators of physical activity level showed that immigrants were more likely to engage in physical activity of at least moderate intensity at least once a week, and also less likely to spend 6 or more hours on sedentary activities. In a prior study of low-income, minority families, a report showed that "non-US-born (vs. US-born) parents had less screen exposure" (Cespedes et al., 2013). Considering the specific directions of these proximal determinants of obesity among immigrants, it is not surprising that most immigrants were in the normal weight category while most native-born participants were in the obese category. The specific directions of physical activity behavior observed among immigrants in this cohort also very likely contribute to the well-documented lower risk of obesity among US immigrants.

It is noteworthy that up to $22 \%$ and $26 \%$ of immigrants and native-born respondents, respectively, did not engage in any physical exercise of at least moderate intensity on at least a weekly basis; and roughly $54 \%$ and $57 \%$ of immigrant and native-born participants respectively did not engage in any muscle training exercise. These numbers are quite concerning, considering the amount of flexibility woven into the current guidelines for physical activity for Americans. Current recommendations are 150 min of moderate exercise per week and at least 2 days of muscle training exercise per week. Public health researchers and practitioners need to continue vigorous education initiatives and policy makers need to enact policies that promote greater levels of physical activity among the general populace.

The recent attempts to reward healthy lifestyle choices in the economic models of insurance policies (Naito and Higgins, 2012) should be tailored toward facilitating the favorable physical activity behavior observed among immigrants. Most insurance policies currently have lower premiums for non-smokers, as well as incentives targeting healthy diets and physical activity among their clientele (Berman et al., 2014). A comprehensive review of numerous policies aimed at preventing overweight and obesity identified ethically sound and objective lifestyle interventions worthy of consideration (Ten Have et al., 2011). The factors identified in our study can be further integrated into medical, life and other insurance policies and harnessed toward promoting behavioral choices that lower the incidence of obesity in the US.
Nevertheless, care must be taken not to overlook equally important health issues affecting both the US-born and immigrant populations.

Our analysis is the first known detailed review of physical activity behavior comparing US immigrants and native-born adults. Nonetheless, our study has important limitations that should be considered. The retrospective nature of the data limits our ability to fully control for potential biases and confounders. Furthermore, we could not assess the effects of acculturation among the study participants due to the small sample size of immigrants who have lived in the US for 15 or more years which under-powered such analysis. Also, participants included in the dataset cannot be followed longitudinally to determine long term outcomes. Although we observed missing data with a number of the variables utilized, the amount of missing data was small and is unlikely to significantly alter the findings from our analyses. Notwithstanding the above-stated limitations, this study provides a great insight into physical activity behavior comparing US immigrants and native-born adults and offers a background for future prospective studies.

\section{Conclusion}

Our analysis of physical activity behavior among US immigrants and native-born adults showed associations of higher levels of physical activity with lower prevalence of obesity among immigrants. Prospective studies with larger samples, adequate follow up of immigrants (from time of entry into the US onwards), and subsequent generations matched US-born and immigrant participants are crucial in exploring the roles of various demographic, social, economic, and cultural factors on proximal determinants of obesity. Such prospective studies will serve to eliminate the apparent biases of a retrospective analysis and guide in the formulation of targeted interventions.

\section{Data availability}

The datasets analyzed during the current study are publicly available in the Health Information National Trends Survey (HINTS) repository of the National Cancer Institute (NCI) (https://hints.cancer.gov/).

Received: 31 July 2019; Accepted: 20 March 2020; Published online: 22 April 2020

\section{References}

Agaku IT, Adisa AO, Ayo-Yusuf OA, Connolly GN (2014) Concern about security and privacy, and perceived control over collection and use of health information are related to withholding of health information from healthcare providers. J Am Med Inf Assoc 21:374-378

Akresh IR (2008) Overweight and obesity among foreign-born and U.S.-born Hispanics. Biodemogr Soc Biol 54:183-199

American Heart Association Nutrition, C., Lichtenstein AH, Appel LJ, Brands M, Carnethon M, Daniels S, Franch HA, Franklin B, Kris-Etherton P, Harris WS, Howard B, Karanja N, Lefevre M, Rudel L, Sacks F, Van Horn L, Winston M, Wylie-Rosett J (2006) Diet and lifestyle recommendations revision 2006: a scientific statement from the American Heart Association Nutrition Committee. Circulation, 114:82-96

Antecol H, Bedard K (2006) Unhealthy assimilation: why do immigrants converge to American health status levels? Demography 43:337-360

Bennett GG, Wolin KY, Askew S, Fletcher R, Emmons KM (2007) Immigration and obesity among lower income blacks. Obesity (Silver Spring) 15:1391-1394

Berman M, Crane R, Seiber E, Munur M (2014) Estimating the cost of a smoking employee. Tob Control 23:428-433

Cadena BC (2013) Native competition and low-skilled immigrant inflows. J Hum Resour 48:910-944

Camarota SA (2012) Immigrants in the United States: a profile of America's foreign-born population. Center for Immigration Studies, Washington 
Cawley J, Meyerhoefer C (2012) The medical care costs of obesity: an instrumental variables approach. J Health Econ 31:219-230

Cespedes EM, McDonald J, Haines J, Bottino CJ, Schmidt ME, Taveras EM (2013) Obesity-related behaviors of US- and non-US-born parents and children in low-income households. J Dev Behav Pediatr 34:541-548

Chooi YC, Ding C, Magkos F (2019) The epidemiology of obesity. Metabolism 92:6-10

Connor P, Ruiz N (2019) Majority of U.S. public supports high-skilled immigration. https://www.pewresearch.org/global/2019/01/22/majority-of-u-s-publicsupports-high-skilled-immigration/. Accessed 1 Oct 2019

Goel MS, McCarthy EP, Phillips RS, Wee CC (2004) Obesity among US immigrant subgroups by duration of residence. JAMA 292:2860-2867

Grieco EM, Acosta YD, De La Cruz GP, Gambino C, Gryn T, Larsen LJ, Trevelyan EN, Walters NP (2010) The foreign-born population in the United States. U.S. Census Bureau, Washington

Hales CM, Fryar CD, Carroll MD, Freedman DS, Aoki Y, Ogden CL (2018) Differences in obesity prevalence by demographic characteristics and urbanization level among adults in the United States, 2013-2016. JAMA 319:2419-2429

Himmelgreen DA, Perez-Escamilla R, Martinez D, Bretnall A, Eells B, Peng Y, Bermudez A (2004) The longer you stay, the bigger you get: length of time and language use in the U.S. are associated with obesity in Puerto Rican women. Am J Phys Anthropol 125:90-96

Jacobs EM (2019) Pathways to permanence: legal status transitions as a key mechanism in skilled migrant selection and settlement. Front Sociol. 4:1-15

Juarez DT, Samoa RA, Chung RS, Seto TB (2010) Disparities in health, obesity and access to care among an insured population of Asian and Pacific Islander Americans in Hawai'i. Hawaii Med J 69:42-46

Kaplan MS, Huguet N, Newsom JT, McFarland BH (2004) The association between length of residence and obesity among Hispanic immigrants. Am J Prev Med 27:323-326

Khaodhiar L, McCowen KC, Blackburn GL (1999) Obesity and its comorbid conditions. Clin Cornerstone 2:17-31

Koya DL, Egede LE (2007) Association between length of residence and cardiovascular disease risk factors among an ethnically diverse group of United States immigrants. J Gen Intern Med 22:841-846

Muller AM, Alley S, Schoeppe S, Vandelanotte C (2016) The effectiveness of e-\& mHealth interventions to promote physical activity and healthy diets in developing countries: a systematic review. Int J Behav Nutr Phys Act 13:109

Naito NA, Higgins ST (2012) Controlling health care costs in the military: the case for using financial incentives to improve beneficiary personal health indicators. Prev Med 55(Suppl.):S113-S115

Nelson DE, Kreps GL, Hesse BW, Croyle RT, Willis G, Arora NK, Rimer BK, Viswanath KV, Weinstein N, Alden S (2004) The Health Information National Trends Survey (HINTS): development, design, and dissemination. J Health Commun, 9:443-460. discussion 81-84

Ng T, McMahanb S, Mouttapac M, Tanjasirid SP, Beam W (2009) Comparison of Body Mass Index (BMI) categories based on Asian and Universal standards and language spoken at home among Asian American University students. Am J Health Educ 40:37-44

Ogden CL, Carroll MD, Kit BK, Flegal KM (2012) Prevalence of obesity and trends in body mass index among US children and adolescents, 1999-2010. JAMA 307:483-490

Ogden CL, Carroll MD, Kit BK, Flegal KM (2014) Prevalence of childhood and adult obesity in the United States, 2011-2012. JAMA 311:806-814

Prentice AM (2006) The emerging epidemic of obesity in developing countries. Int J Epidemiol 35:93-99
Singh GK, Miller BA (2004) Health, life expectancy, and mortality patterns among immigrant populations in the United States. Can J Public Health 95:I14-121

Ten Have M, De Beaufort ID, Teixeira PJ, Mackenbach JP, Van Der Heide A (2011) Ethics and prevention of overweight and obesity: an inventory. Obes Rev 12:669-679

Vuong QH (2018) Sociodemographic factors influencing vietnamese patient satisfaction with healthcare services and some meaningful empirical thresholds. Iran J Public Health 47:119-126

Wadden TA, Steen SN, Wingate BJ, Foster GD (1996) Psychosocial consequences of weight reduction: how much weight loss is enough? Am J Clin Nutr 63:461S-465S

Weinsier RL, Hunter GR, Heini AF, Goran MI, Sell SM (1998) The etiology of obesity: relative contribution of metabolic factors, diet, and physical activity Am J Med 105:145-150

Wen M, Kowaleski-Jones L, Fan JX (2013) Ethnic-immigrant disparities in total and abdominal obesity in the US. Am J Health Behav 37:807-818

\section{Author contributions}

Both authors (1) contributed to the conception and design, acquisition of data, analysis and interpretation of data; and (2) have been involved in drafting the manuscript and revising it critically for important intellectual content; and (3) have given final approval of the version to be published; and (4) agree to be accountable for all aspects of the work in ensuring that questions related to the accuracy or integrity of any part of the work are appropriately investigated and resolved.

\section{Competing interests}

The authors declare no competing interests.

\section{Additional information}

Correspondence and requests for materials should be addressed to O.B.A.

Reprints and permission information is available at http://www.nature.com/reprints

Publisher's note Springer Nature remains neutral with regard to jurisdictional claims in published maps and institutional affiliations.

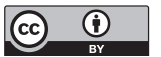

Open Access This article is licensed under a Creative Commons Attribution 4.0 International License, which permits use, sharing, adaptation, distribution and reproduction in any medium or format, as long as you give appropriate credit to the original author(s) and the source, provide a link to the Creative Commons license, and indicate if changes were made. The images or other third party material in this article are included in the article's Creative Commons license, unles indicated otherwise in a credit line to the material. If material is not included in the article's Creative Commons license and your intended use is not permitted by statutory regulation or exceeds the permitted use, you will need to obtain permission directly from the copyright holder. To view a copy of this license, visit http://creativecommons.org/ licenses/by/4.0/.

(c) The Author(s) 2020 